\title{
On the models for the distribution of examination score for projecting the demand for Korean Long-Term Care Insurance
}

\author{
Sophia Nicole Javal ${ }^{a}$, Hyuk-Sung Kwon ${ }^{1, a}$ \\ ${ }^{a}$ Department of Statistics and Actuarial Science, Soongsil University, Korea
}

\begin{abstract}
The Korean Long-Term Care Insurance (K-LTCI) provides financial support for long-term care service to people who need various types of assistance with daily activities. As the number of elderly people in Korea is expected to increase in the future, the demand for long-term care insurance would also increase over time. Projection of future expenditure on K-LTCI depends on the number of beneficiaries within the grading system of K-LTCI based on the test scores of applicants. This study investigated the suitability of mixture distributions to the model K-LTCI score distribution using recent empirical data on K-LTCI, provided by the National Health Insurance Service (NHIS). Based on the developed mixture models, the number of beneficiaries in each grade and its variability under the current grading system were estimated by simulation. It was observed that a mixture model is suitable for K-LTCI score distribution and may prove useful in devising a funding plan for K-LTCI benefit payment and investigating the effects of any possible revision in the K-LTCI grading system.
\end{abstract}

Keywords: demand, grading system, long-term care insurance, mixture distributions, projection, simulation

\section{Background}

The Korean Long-Term Care Insurance (K-LTCI) was introduced in 2008 by the National Health Insurance Service (NHIS) for the purpose of providing financial support to people who need assistance with daily activities. With the rapid aging of the population, the K-LTCI has been playing an important role in providing a social security system for the elderly in Korea. When K-LTCI was introduced, the premium rate was $0.21 \%$ of the salary. However, the premium sharply increased to $0.68 \%$ in 2020 to reflect increased cost of operations. Population projection by Statistics Korea indicates K-LTCI beneficiaries will keep increasing, and so will the associated costs. Thus, cost projection is an important task and will help provide information to devise an appropriate financial plan aimed at maintaining the sustainability of K-LTCI.

The extent of financial support from K-LTCI depends on the grade defined by the range of examination scores of applicants indicating the degree of care level needed. Therefore, the distribution of scores assigned to K-LTCI applicants can be used to model the proportion of beneficiaries in each grade level. Accordingly, annual cost of K-LTCI in future years can be estimated by the projected number of beneficiaries by year and a comprehensive model for cost structure.

The NHIS provides monthly data on the number of beneficiaries in each grade level by sex and age group upon request; this data allows us to construct a model for the distribution of scores assigned to K-LTCI applicants. In order to secure an appropriate model for score distribution, various types of model structure should be explored. The goal of this study is to investigate a variety of mixture models for score distribution and to compare them with the models explored in Kwon et al. (2016). There has not been any

\footnotetext{
${ }^{1}$ Corresponding author: Department of Statistics and Actuarial Science, Soongsil University, 369 Sangdo-ro, Dongjak-gu, Seoul 06978, Korea. E-mail: hskwon@ssu.ac.kr
}

Published 31 July 2021 / journal homepage: http://csam.or.kr

(C) 2021 The Korean Statistical Society, and Korean International Statistical Society. All rights reserved. 
discussion on demand and expenditure projections for K-LTCI services since the revision of the K-LTCI scoring system in 2018. This study expects to initiate the discussion on how the current grading system might affect such projections.

The developed model is expected to be utilized in the following analyses. The main purpose of the model for score distribution is to estimate the number of beneficiaries in each grade of K-LTCI in future years. It is desirable that the estimated number of beneficiaries is interpreted with its variability. Simulation based on the developed model allows for quantifying the variability. In addition, the grading structure has been revised four times ever since K-LTCI was introduced. When further revisions on the grading structure are considered, a model for score distribution can be used to observe the effect of revision on the number of beneficiaries in each of the revised grades.

Aging population is common to many developed countries. To improve the quality of life for elderly population, every country has developed its own long-term care system as a form of social security. As projection of the number of beneficiaries and of the associated costs of long-term care system are important to guide policymaking, there has been adequate research on estimating future demands and expenditures of long-term care.

A number of previous studies have used a cell-based approach to estimate the number of persons requiring long-term care. This approach classifies population into a set of sub-populations, termed cells, based on the factors affecting the utilization of long-term care. Then, based on the projected population and utilization rate of long-term care in each cell, the number of patients who need long-term care in each is derived. Wittenberg et al. (1998) applied the approach to estimate the elderly population in England. The authors defined cells in terms of age, gender, dependency, and household composition and derived future demand for long-term care. Further, Linda et al. (2007) used a similar method to project the total cost of long-term care in Germany, Italy, Spain, and the UK.

Several studies have employed the cell-based approach to project the number of beneficiaries and the associated expenditure under K-LTCI. Yun and Kwon (2010) used sample data and considered several scenarios to obtain the proportion of K-LTCI beneficiaries in each cell defined by age, gender, household type, and health status, which are all considered drivers of long-term care expenditure. Kim and Kwon (2012), Lee and Choi (2014), and Lee and Moon (2017) followed up the discussion suggesting modified cell-based approaches.

Another approach for projection of demand for and cost of long-term care was suggested by Rickayzen and Walsh (2002) who utilized a multi-state model to reflect possible changes in health status, categorized according to the severity of functional disability, to estimate long-term care demand in UK. They constructed a mathematical formula to obtain transition probabilities from one state to another. Based on the transition probabilities, the number of persons in each state in future years is estimated based on their current proportions in each state. Their work was followed by Karlsson et al. (2006) in which future cost of long-term care was projected.

Leung (2004) constructed a multi-state model to project the future demand for and cost of long-term care for the elderly population in Australia. Based on the National Long-Term Care Survey (NLTCS) in the USA, Chan et al. (2004) employed a multi-state model to project long-term care demand in Hong Kong. Kwon and Lee (2011) projected the number of K-LTCI beneficiaries in each grade and the associated total cost for future years using a multi-state model. Furthermore, Kwon (2013) analyzed the expected number of years during which an individual will need long-term care and estimated the actuarial present value of the future cost of long-term care, all within a multi-state model framework.

Additionally, several studies used scenario analysis for projection. Choi et al. (2010) estimated the number of K-LTCI beneficiaries based on various scenarios, and Choi and Lee (2011) evaluated the effect of possible scenarios of future policy expanding the eligibility of K-LTCI benefit on the increase in the number of beneficiaries. Lagergren et al. (2018) performed scenario analysis for projecting long-term care demand and expenditure in Japan and Sweden.

Other approaches can be found as well in recent literatures. Kwon et al. (2016) suggested a simulation 
Table 1: Changes in the grade level system of K-LTCI

\begin{tabular}{|c|c|c|c|c|c|}
\hline \multirow{2}{*}{ Score range } & \multicolumn{5}{|c|}{ Phases } \\
\hline & I (2008.7-2012.6) & II (2012.7-2013.6) & III (2013.7-2014.6) & IV (2014.7-2017.12) & V (2018.1-current) \\
\hline $31.3-39.9$ & Non-grade C & Non-grade C & Non-grade C & Non-grade C & $\begin{array}{c}\text { Non-grade C or } \\
\text { Cognitive Assistance }\end{array}$ \\
\hline $40.0-44.9$ & Non-grade B & Non-grade B & Non-grade B & Non-grade B & $\begin{array}{c}\text { Non-grade B or } \\
\text { Cognitive Assistance }\end{array}$ \\
\hline $45.0-50.9$ & \multirow{2}{*}{ Non-grade A } & \multirow[t]{2}{*}{ Non-grade A } & Non-grade A & $\begin{array}{l}\text { Non-grade A } \\
\text { or Grade } 5\end{array}$ & $\begin{array}{c}\text { Non-grade A } \\
\text { or Grade } 5\end{array}$ \\
\hline $\begin{array}{l}51.0-52.9 \\
53.0-54.9\end{array}$ & & & \multirow{3}{*}{ Grade 3} & \multirow{2}{*}{ Grade 4} & \multirow{2}{*}{ Grade 4} \\
\hline $55.0-59.9$ & \multirow{2}{*}{ Grade 3} & \multirow[t]{2}{*}{ Grade 3} & & & \\
\hline $60.0-74.9$ & & & & Grade 3 & Grade 3 \\
\hline $75.0-94.9$ & Grade 2 & Grade 2 & Grade 2 & Grade 2 & Grade 2 \\
\hline $95.0-154.3$ & Grade 1 & Grade 1 & Grade 1 & Grade 1 & Grade 1 \\
\hline
\end{tabular}

method based on K-LTCI score distribution for estimating the number of persons in each grade. Xu and Chen (2019) applied Bayesian Quantile Regression to understand the relationship between the incidence of chronic diseases and long-term care demand and derived the number of patients who would need longterm care in the future. Vanella et al. (2020) quantified future variability of population, which affects long-term care demand, due to uncertainty in mortality rates. The authors used the Lee-Carter model to simulate various scenarios in future mortality rates and derived a possible range of long-term care demands.

The main contribution of this study is extending suitable distribution models, by investigating mixture models, of K-LTCI scores assigned to the applicants of K-LTCI. Since the grading structure of K-LTCI has been revised recently, suitability of models for the distribution of assigned K-LTCI scores based on updated data reflecting current grading structure of K-LTCI should be evaluated. This study suggests up-to-date models which is suitable for modeling K-LTCI score distribution using data from the current grading structure of K-LTCI. Finally, a more comprehensive simulation method to estimate the number of K-LTCI beneficiaries in the future based on the developed model is discussed.

The paper is organized as follows. The process for assigning grade level in K-LTCI and the data analyzed in this study are introduced in Sections 2 and 3. The selection of best mixture models and comparison with other models are discussed in Section 4. Using simulation, projections of K-LTCI beneficiaries by grade are described in Section 5, while Section 6 provides the concluding remarks.

\section{Grading Structure of K-LTCI}

As the detailed information on the K-LTCI is addressed in Kwon et al. (2016), this study addresses updated grading structure of K-LTCI. The assigned K-LTCI examination score to applicants of K-LTCI benefit varies from 31.3 to 154.3 . Higher scores indicate severe health conditions requiring higher care level. Initially K-LTCI had six grades defined according to score ranges; this grading system has been revised four times since introduction. Table 1 summarizes the historical changes in the K-LTCI grading system and the grading structure during each phase of K-LTCI.

At the beginning of 2018 , the grading system was revised. The revision was to introduce a grade called Cognitive Assistance. The grade shares score range with Non-grade B and C. Similar to the difference between Grade 5 and Non-grade A, an applicant of K-LTCI with dementia whose K-LTCI score is between 31.3 and 44.9 is entitled to Cognitive Assistance and eligible for K-LTCI benefits. Historically, the K-LTCI grading system has been revised to expand the number of beneficiaries and to improve homogeneity in terms of the health condition, of persons in the same grade.

Revising the grading system affects the total cost of K-LTCI since available services such as the monthly limit of financial support and the type of service depend on the assigned grade. Therefore, the 
Table 2: The number of beneficiaries of K-LTCI

\begin{tabular}{ccccc}
\hline \hline & \multicolumn{3}{c}{ Male } & \multicolumn{2}{c}{ Female } \\
\cline { 2 - 5 } \cline { 3 - 5 } & Over 65 & Under 65 & Over 65 & Under 65 \\
\hline 2016 & 119,600 & 12,897 & 347,627 & 9,404 \\
2017 & 135,722 & 13,393 & 393,632 & 9,690 \\
2018 & 155,832 & 14,180 & 446,170 & 10,322 \\
2019 & 180,443 & 15,099 & 509,728 & 10,759 \\
2020 & 204,052 & 15,169 & 572,858 & 10,553 \\
\hline \hline
\end{tabular}

distribution of assigned scores should be carefully understood and modeled to estimate the number of people in each grade and their variability. Based on the estimation, the structure of services and premium rates should be adjusted accordingly and reflected in the financial management to keep the K-LTCI system sustainable. At the same time, characteristics of benefit payment and usage of service among beneficiaries of the same grade should be analyzed periodically to consider any possible revision in the grading system and to provide more practical support to people with long-term care needs.

The main challenge in modeling K-LTCI score distribution is to fit parametric models using grouped data based on current grading structure. That is, the number of beneficiaries in each grade, separated by several breakpoints, is only available information for estimating parameters of a model. A suitable model should reflect overall shape of empirical distribution while accommodating the proportion of each grade level in experience data, which will allow us to properly estimate future demand of K-LTCI and its variability in each grade. Also, models should be updated according to the revision of K-LTCI grading system that involves a change in the set of the breakpoints.

\section{Data}

Data on the number of persons, separated by sex and age group, in each grade of K-LTCI at the end of calendar month can be obtained upon request from the NHIS. As population data provided by Statistics Korea is based on the mid-year population, which is used in the simulation discussed in Section 6, we obtained the number of persons in each grade at the end of June in recent five years. Because only applicants with dementia are covered by K-LTCI for ages under 65, the score distribution model should be constructed separately by age group.

Table 2 summarizes the number of beneficiaries being covered by K-LTCI at the mid-point of each calendar year; the number reflects the overall increasing trend for both age groups. The significant increase in the number of beneficiaries in the older age group is due to the increase in elderly population and the introduction of the Cognitive Assistance grade. The annual rate of increase in the number of older age beneficiaries from 2016 to 2020 is $14.29 \%$ for male and $13.30 \%$ for female. The number of female beneficiaries is roughly triple the number of male beneficiaries each year; This can be explained by the fact that there are more female survivors in elderly population, and that the incidence of Alzheimer's disease, one of the commonest diseases requiring long-term care, is higher in females.

The annual rate of increase of the number of younger age beneficiaries between 2016 and 2020 was $4.14 \%$ for male and $2.92 \%$ for females; this may be due to the decrease in fertility rate over the past decades. That is, population in younger ages exposed to deterioration of health condition requiring support for daily activities did not increase as much as population in older ages. The number of female beneficiaries less than 65 years decreased in 2020 compared to that in the previous year. Unlike in the older age group, the number of male beneficiaries in the less-than- 65 group is about 1.5 times the number of female beneficiaries, mainly because the incidence of vascular dementia due to stroke is more prevalent in men. Comparing the number of beneficiaries between the two age groups, the number of beneficiaries over 65 is higher than that of the beneficiaries under 65. The proportion of beneficiaries over 65 in 2020 was $93.1 \%$ for male and $98.2 \%$ for female. Therefore, it is expected that total cost of K-LTCI mostly depends on the beneficiaries aged over 65 . 
Table 3: The number of beneficiaries of K-LTCI

\begin{tabular}{|c|c|c|c|c|}
\hline \multirow{2}{*}{ Grade } & \multicolumn{2}{|c|}{ Under 65} & \multicolumn{2}{|c|}{ Over 65} \\
\hline & Male & Female & Male & Female \\
\hline Grade 1 & 1,873 & 1,598 & 10,283 & 28,717 \\
\hline Grade 2 & 1,747 & 1,404 & 20,134 & 61,683 \\
\hline Grade 3 & 5,140 & 3,401 & 60,282 & 159,957 \\
\hline Grade 4 & 5,385 & 3,343 & 88,057 & 251,812 \\
\hline Grade 5 & 801 & 617 & 20,701 & 59,194 \\
\hline Cognitive Assistance & 223 & 190 & 4,595 & 11,495 \\
\hline Non-grade A & 1,715 & 1,024 & 20,056 & 53,647 \\
\hline Non-grade B & 712 & 388 & 18,814 & 41,166 \\
\hline Non-grade C & 238 & 113 & 5,180 & 8,082 \\
\hline Total & 17,834 & 12,078 & 248,102 & 675,753 \\
\hline
\end{tabular}

Male under 65

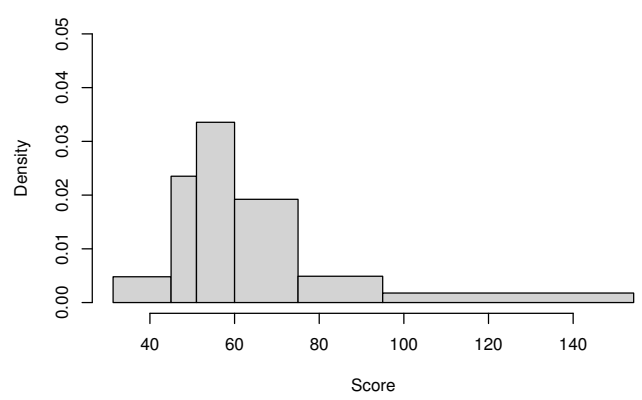

Male over 65

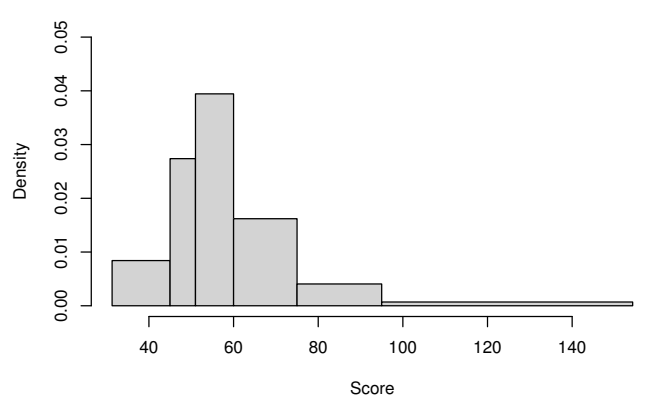

Female under 65

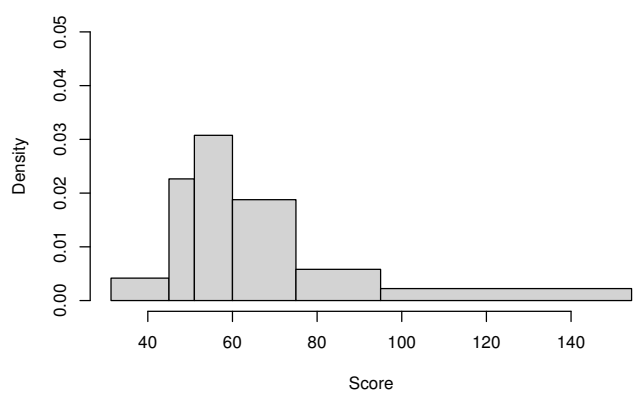

Female over 65

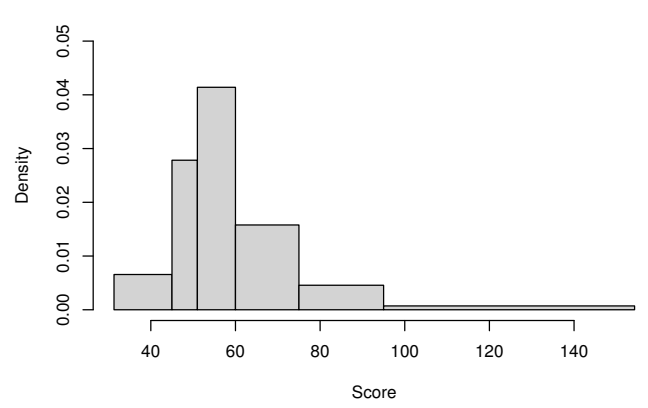

Figure 1: Histogram of the number of beneficiaries according to K-LTCI score.

As the distribution of K-LTCI score among applicants who have a grade assigned from K-LTCI is modeled in this study, the number of persons in each grade under the current grading system is used. Table 3 presents the number of persons in each grade separated by sex and age group at the end of June 2020. Table 3 is converted to histogram in Figure 1 according to the current grading system of K-LTCI. The overall shape of the histograms is similar to the plots shown in Kwon et al. (2016), although the grading system has been revised since then. Distribution models should reflect the patterns observed in Figure 1 that the density is increasing from the lowest possible score (31.3) to some point near the boundary of Grades 4 and 5, and then decrease gradually to the highest score (154.3). Since the range of available examination score in the K-LTCI grading system is confined, the parametric distribution model should be adjusted for support in that range. 


\section{Comparison of models}

\subsection{Mixture models}

Mixing distributions is one of the frequently used methods to construct statistical models using two or more parametric distributions to fit an empirical distribution when any single parametric distribution is not able to accommodate the characteristic of distribution of given data. Various single distributions, referring an inventory of continuous distributions in Appendix A of Klugman et al. (2019), did not show desirable fitting results to empirical K-LTCI score distributions in Figure 1, which is consistent with the results in Kwon et al. (2016). Therefore, mixture distributions were considered and compared with previously suggested spliced models. A brief description of the two-component mixture models used in this study follows.

Consider two probability density functions denoted by $f_{1}(x)$ and $f_{2}(x)$ and corresponding distribution functions denoted by $F_{1}(x)$ and $F_{2}(x)$. Then, for a value of $\omega(0<\omega<1)$, the probability density function and distribution function of two-omponent mixture distribution, denoted by $f(x)$ and $F(x)$, are expressed by

$$
\begin{aligned}
\left.f_{(} x\right) & =\omega \cdot f_{1}(x) x+(1-\omega) \cdot f_{2}(x) \\
F(x) & =\omega \cdot F_{1}(x)+(1-\omega) \cdot F_{2}(x)
\end{aligned}
$$

Although the parametric distributions used in this study have support over $[0, \infty]$ or $[-\infty, \infty]$, the range of K-LTCI score is $[31.3,154.3]$. Therefore, the range of $f(x)$ should be adjusted by dividing by $F(154.3)-$ $F(31.3)$ so that the adjusted probability density function has support on available K-LTCI score range. Then, since we have grouped data according to break points dividing grades of K-LTCI, the likelihood function $L_{m}(\theta)$ where $\theta$ indicates parameters included in the model is expressed by

$$
L_{m}(\underline{\theta})=\prod_{i=1}^{6}\left[\frac{F\left(x_{i}\right)-F\left(x_{i-1}\right)}{F(154.3)-F(31.3)}\right]^{n_{i}}
$$

where $x_{0}, x_{1}, \ldots, x_{6}$ are $31.3,40.0, \ldots, 154.3$, the current break points of K-LTCI grades corresponding to the last column of Table 1 and $n_{i}$ is the number of persons having a K-LTCI grade equivalent to $i^{\text {th }}$ lowest score interval. Parameters involved in $f_{1}(x)$ and $f_{2}(x)$ together with $\alpha$ are estimated using maximum likelihood estimation. Various combinations of two component distributions associated with equation (4.1) were considered and models were selected based on Akaike Informaion Criterion (AIC). Considering parsimony of a model based on grouped data with only six breakpoints, two-components model was preferred unless the fitting result is undesirable.

As expressed in equation (4.3), parameters are included in both numerator and denominator in each term of the product. Therefore, finding maximum likelihood estimates of parameters is non-linear optimization problem as the exponent of each term in the product is a lot greater than total number of parameters. For optimization, Microsoft Excel Solver function was used to obtain parameters maximizing log-likelihood function using various initial values of parameters as there may exist many local maxima in the target function.

For both males and females under 65 years, a combination of two Burr distributions was found to be the most appropriate model. Also, a combination of inverse paralogistic distribution and inverse Weibull distribution was selected for both sexes over age 65. Together with beta distribution used in the next section, the form of a component probability density function in the selected models in this study is expressed as follows

- Burr distribution: $\frac{\alpha \gamma(x / \theta)^{\gamma}}{x\left[1+(x / \theta)^{\gamma}\right]^{\alpha+1}}, \quad x \in(0, \infty)$

- Inverse paralogistic distribution: $\frac{\tau^{2}(x / \theta)^{\tau^{2}}}{x\left[1+(x / \theta)^{\tau}\right]^{\tau+1}}, \quad x \in(0, \infty)$ 
Table 4: Selected mixture models

\begin{tabular}{|c|c|c|c|c|c|}
\hline Group & Sex & Component & Estimated parameters & $\omega$ & AIC \\
\hline \multirow{11}{*}{ Under 65} & \multirow{5}{*}{ Male } & & $\hat{\theta}=43.8562$ & \multirow{5}{*}{0.6953} & \multirow{5}{*}{$58,498.58$} \\
\hline & & $f_{1}(x):$ Burr & $\hat{\gamma}=21.4845$ & & \\
\hline & & & $\begin{array}{l}\hat{\alpha}=0.0866 \\
\hat{\hat{\theta}}-60.1023\end{array}$ & & \\
\hline & & \multirow[b]{2}{*}{$f_{2}(x):$ Burr } & $\hat{\theta}=69.1023$ & & \\
\hline & & & $\begin{array}{l}\hat{\gamma}=15.1080 \\
\hat{\alpha}=7.1377\end{array}$ & & \\
\hline & \multirow{6}{*}{ Female } & & $\hat{\theta}=44.6004$ & \multirow{6}{*}{0.6953} & \multirow{6}{*}{$58,498.58$} \\
\hline & & $f_{1}(x)$ : Burr & $\hat{\gamma}=20.0319$ & & \\
\hline & & & $\hat{\alpha}=0.0845$ & & \\
\hline & & \multirow{3}{*}{$f_{2}(x):$ Burr } & $\hat{\theta}=69.4587$ & & \\
\hline & & & $\hat{\gamma}=15.1050$ & & \\
\hline & & & $\hat{\alpha}=7.1442$ & & \\
\hline \multirow{6}{*}{ Over 65} & \multirow{3}{*}{ Male } & $f_{1}(x)$ : Inverse paralogistic & $\hat{\tau}=3.8193$ & \multirow{3}{*}{0.4915} & \multirow{3}{*}{$790,395.2 ?$} \\
\hline & & & $\hat{\theta}=36.3763$ & & \\
\hline & & $f_{2}(x)$ : Inverse Weibull & $\begin{array}{l}\hat{\tau}=9.1044 \\
\hat{\theta}=54.1579\end{array}$ & & \\
\hline & \multirow{3}{*}{ Female } & $f_{1}(x)$ : Inverse paralogistic & $\hat{\tau}=4.8193$ & \multirow{3}{*}{0.5085} & \multirow{3}{*}{$2,131,460.64$} \\
\hline & & & $\hat{\theta}=39.4435$ & & \\
\hline & & $f_{2}(x)$ : Inverse Weibull & $\begin{array}{l}\hat{\tau}=13.0356 \\
\hat{\theta}=53.2873\end{array}$ & & \\
\hline
\end{tabular}

- Inverse Weibull distribution: $\frac{\tau(x / \theta)^{\tau} e^{-(x / \theta)^{\tau}}}{x}, \quad x \in(0, \infty)$

- Beta distribution: $\frac{\Gamma(\alpha) \Gamma(\beta)}{\Gamma(\alpha+\beta)} \cdot \frac{(x-a)^{\alpha-1}(b-x)^{\beta-1}}{(b-a)^{\alpha+\beta-1}}, \quad x \in(a, b)$

Component distributions of mixture models, their estimated parameters and AIC values of selected models are summarized in Table 4. In addition, Figure 2 presents the graphs of selected models superposed on the histograms in Figure 1.

In addition, for the best five mixture models, Bayesian information criterion (BIC), mean absolute percentage error (MAPE), and comparison of $F(x)$ with corresponding value of empirical distribution at the breakpoints were presented in Appendix. It was found that the selected models based on AIC tend to have desirable values of discrepancy measures so that mixture models can be considered suitable for K-LTCI score distribution model.

\subsection{Comparison with spliced models}

Splicing is another flexible method to fit an empirical distribution that was explored to model K-LTCI score distribution in Kwon et al. (2016). A spliced model uses two or more distribution functions that are applied to disjoint intervals. If two probability density functions, denoted by $g_{1}(x)$ and $g_{2}(x)$, are used, then spliced model $g(x)$ having support on $\left[c_{0}, c_{1}\right]$ with break point $b\left(c_{0}<b<c_{1}\right)$ is expressed as

$$
g(x)= \begin{cases}u \cdot \frac{g_{1}(x)}{G_{1}(b)-G_{1}\left(c_{0}\right)}, & c_{0} \leq x<b, \\ (1-u) \cdot \frac{g_{2}(x)}{G_{2}\left(c_{1}\right)-G_{2}(b)}, & b \leq x \leq c_{1},\end{cases}
$$

where $G_{1}(x)$ and $G_{2}(x)$ are distribution functions corresponding to $g_{1}(x)$ and $g_{2}(x)$, respectively. In order to model K-LTCI score distribution, $c_{0}=31.3$ and $c_{1}=154.3$ were used. Then, likelihood function $L_{s}(\underline{\theta})$ is expressed as

$$
L_{s}(\underline{\theta})=\prod_{i=1}^{6}\left[G\left(x_{i}\right)-G\left(x_{i-1}\right)\right]^{n_{i}}
$$


Male under 65

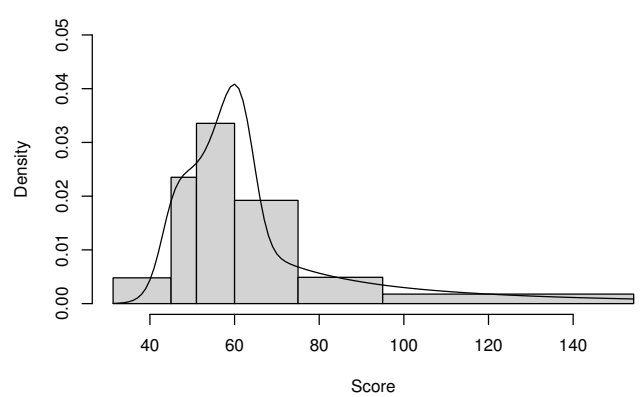

Male over 65

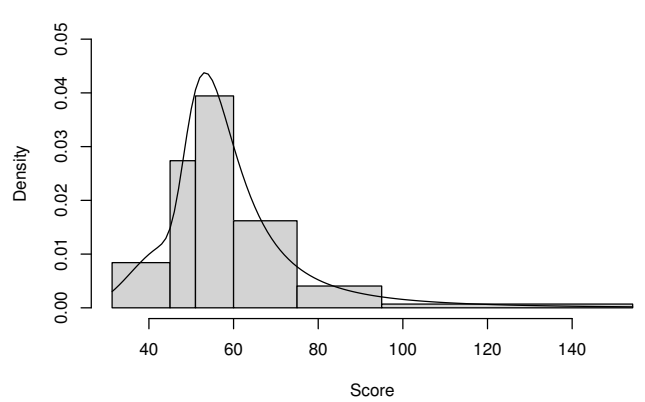

Female under 65

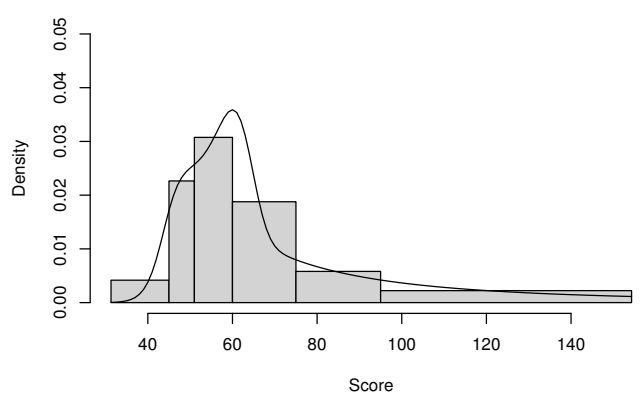

Female over 65

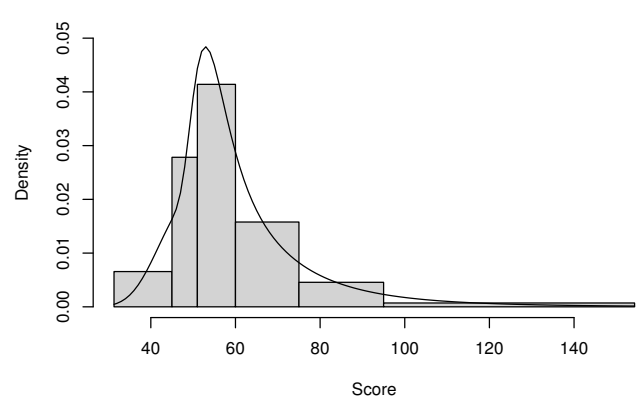

Figure 2: Graphs of selected mixture models.

Table 5: Selected spliced models

\begin{tabular}{|c|c|c|c|c|c|}
\hline Group & Sex & Component & Estimated parameters & $u$ & AIC \\
\hline \multirow{4}{*}{ Under 65} & \multirow{2}{*}{ Male } & $g_{1}(x)$ : Inverse paralogistic & $\begin{array}{l}\hat{\tau}=4.9922 \\
\hat{\theta}=42.9032\end{array}$ & \multirow{2}{*}{0.5088} & \multirow{2}{*}{$58,492.56$} \\
\hline & & $g_{2}(x):$ Beta & $\begin{array}{l}\hat{\alpha}=0.3860 \\
\hat{\beta}=1.5149\end{array}$ & & \\
\hline & \multirow{2}{*}{ Female } & $g_{1}(x)$ : Inverse Weibull & $\begin{array}{l}\hat{\tau}=5.4339 \\
\hat{\theta}=41.9637\end{array}$ & \multirow{2}{*}{0.4699} & \multirow{2}{*}{$40,228.92$} \\
\hline & & $g_{2}(x):$ Beta & $\begin{array}{l}\hat{\alpha}=0.4535 \\
\hat{\beta}=1.5114\end{array}$ & & \\
\hline \multirow{4}{*}{ Over 65} & \multirow{2}{*}{ Male } & $g_{1}(x)$ : Inverse paralogistic & $\begin{array}{l}\hat{\tau}=2.3488 \\
\hat{\theta}=76.3038\end{array}$ & \multirow{2}{*}{0.6344} & \multirow{2}{*}{$790,393.23$} \\
\hline & & $g_{2}(x):$ Beta & $\begin{array}{l}\hat{\alpha}=0.5059 \\
\hat{\beta}=2.9545\end{array}$ & & \\
\hline & \multirow{2}{*}{ Female } & $g_{1}(x):$ Inverse Weibull & $\begin{array}{l}\hat{\tau}=2.9385 \\
\hat{\theta}=68.3062\end{array}$ & \multirow{2}{*}{0.6295} & \multirow{2}{*}{$2,131,458.64$} \\
\hline & & $g_{2}(x):$ Beta & $\begin{array}{l}\hat{\alpha}=0.6005 \\
\hat{\beta}=3.3003\end{array}$ & & \\
\hline
\end{tabular}

where $G(x)$ is distribution function obtained from equation (2.4) and $x_{0}, x_{1}, \ldots, x_{6}$ and $n_{i}$ are the same as in equation (2.3). As a result of mathematical formulation in equations (4.4) and (4.5), the shape of the spliced distribution model is discontinuous at the breakpoint $b$. Even if the estimation process is constrained so that $g_{1}(x)$ and $g_{2}(x)$ be connected at the breakpoint, flexibility of the model decreases and fitting results are likely to be unsatisfactory.

A number of two-component spliced models were investigated with $b=60$, which divides the entire K-LTCI score range into the interval associated with Grades 1-3 and remaining interval. When $b$ is treated as a parameter of a model, the shape of the fitted distribution was not properly matched with empirical 

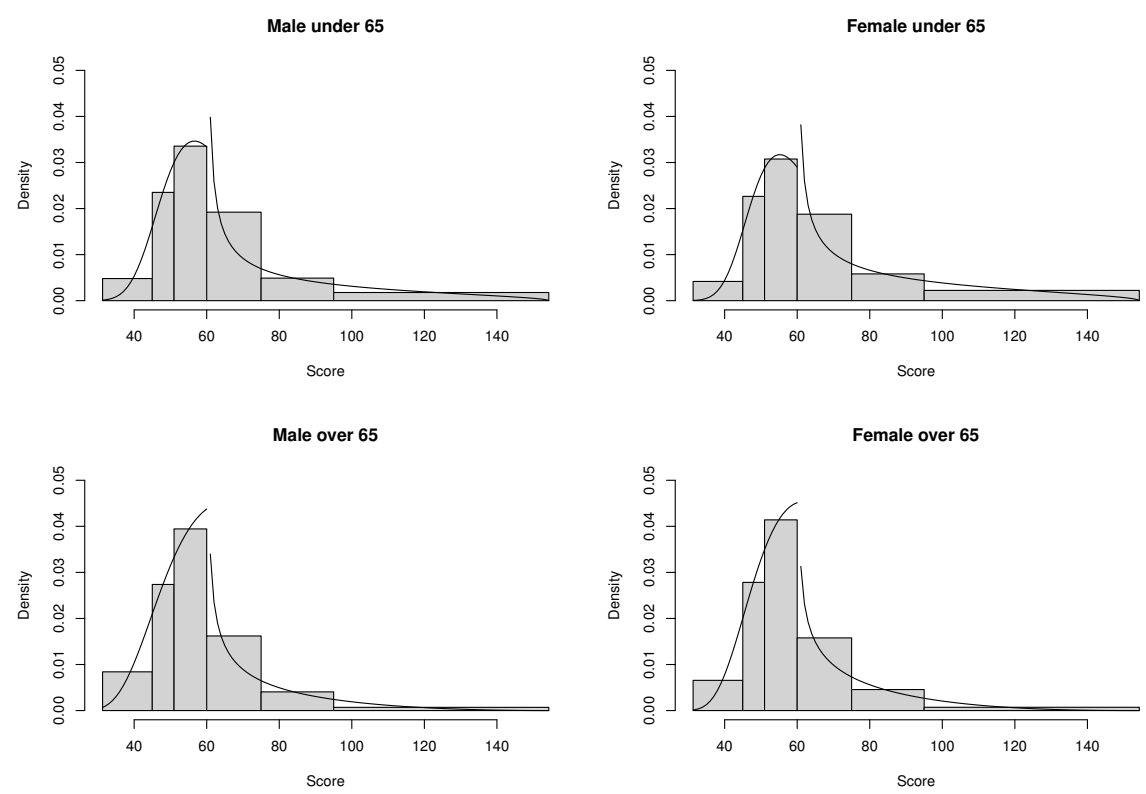

Figure 3: Graphs of selected spliced models.

Table 6: Assumption of the proportion of surviving K-LTCI applicants

\begin{tabular}{|c|c|c|c|c|}
\hline \multirow{2}{*}{$\begin{array}{l}\text { Population } \\
\text { assumption }\end{array}$} & \multicolumn{2}{|c|}{ Male } & \multicolumn{2}{|c|}{ Female } \\
\hline & Over 65 & Under 65 & Over 65 & Under 65 \\
\hline Middle & 0.067193 & 0.000780 & 0.137695 & 0.000576 \\
\hline High & 0.067141 & 0.000779 & 0.140320 & 0.000570 \\
\hline Low & 0.067249 & 0.000781 & 0.140554 & 0.000571 \\
\hline
\end{tabular}

data. Therefore, the $x_{1}, \ldots, x_{5}$ was explored as a value of $b$ and the most optimal value turned out to be $b=60$. Table 5 summarizes the results of estimation of the selected models. Figure 3 gives the graphs of fitted spliced models.

Comparing selected mixture models with the counterparts of the spliced models, the latter attain slightly better AIC values. However, the large jump at the breakpoint of spliced models is remarkable. As discussed in Kwon et al. (2016), this may distort simulation results of observing the effect of possible changes in the K-LTCI grading system. Also, determination of breakpoint of spliced models is another modeling issue, which is not required in mixture models. Therefore, the mixture model has lower model risk than the spliced model for the purpose of scenario analysis on the variation of the K-LTCI grading system.

\section{Simulation}

Since the current K-LTCI grading system was introduced in 2018, there have been no discussions on the projection of the number of beneficiaries and the associated costs. Based on the developed mixture models in Section 5 and other assumptions, the number of K-LTCI beneficiaries in each grade and their variability was projected using simulation. The followings are the descriptions of simulation algorithm and relevant assumptions,

- Step 1. Population structure: The population size of each age group is an important indicator of the degree of risk to health conditions requiring long-term care. Statistics Korea provides projected population by age at the midpoint of each future year up to 2067. There are three scenarios for population 
Male

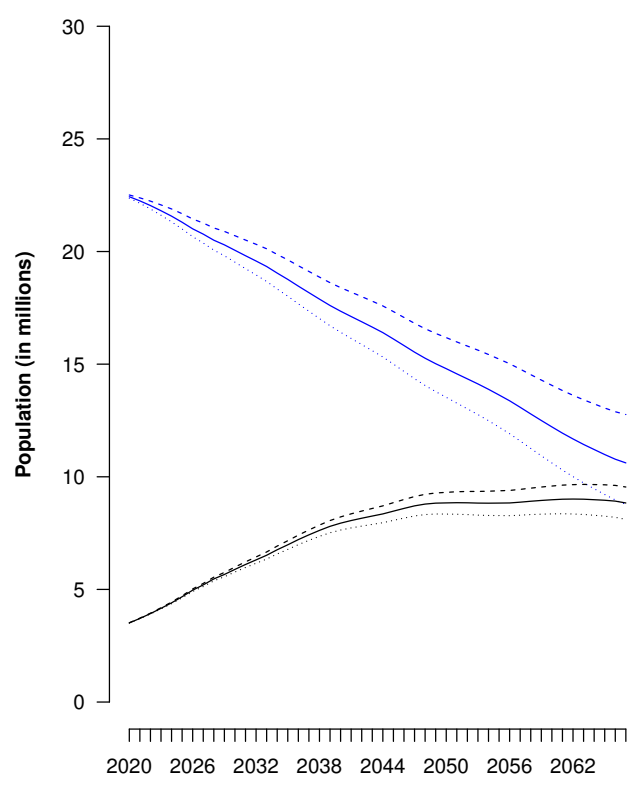

Year
Female

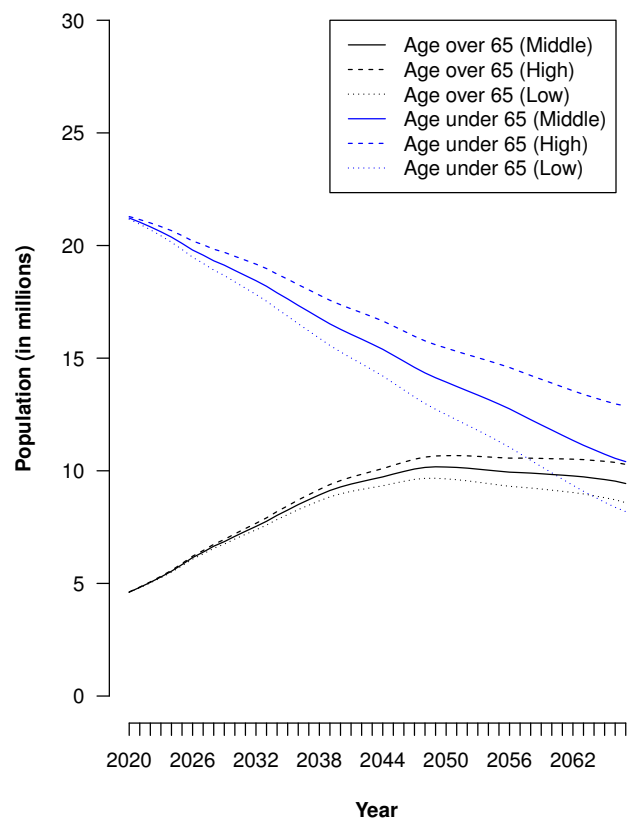

Figure 4: Graphs of selected spliced models.

Table 7: Assumption of the proportion of Grade 5 and Cognitive Assistance

\begin{tabular}{cccccc}
\hline \hline \multirow{2}{*}{ Grade } & \multicolumn{2}{c}{ Male } & & \multicolumn{2}{c}{ Female } \\
\cline { 2 - 3 } \cline { 5 - 6 } & Over 65 & Under 65 & & Over 65 & Under 65 \\
\hline Grade 5 & 0.450004 & 0.266372 & & 0.449838 & 0.328252 \\
Cognitive assistance & 0.116301 & 0.139797 & & 0.135257 & 0.212813 \\
\hline \hline
\end{tabular}

projection: High, Middle, and Low. The Middle scenario is based on the prospect that past trend of demographic factors will continue in the future, while the High scenario indicates an optimistic outlook in which fertility rate is higher and mortality rate is lower than in the Middle scenario and the Low scenario represents its opposite. Future changes in population according to the three scenarios are visualized in Figure 4.

- Step 2. Number of surviving K-LTCI applicants: Out of the number of population in each age group (over/under age 65) and sex obtained in the previous step, the total number of surviving K-LTCI applicants who have K-LTCI score is derived. Based on the number of beneficiaries in Table 2 and the number of persons in Non-grades A, B, and C, the proportion of the number of surviving K-LTCI applicants in corresponding population can be obtained. Using recent three-year population data based on three scenarios, the assumptions for the proportions were set as shown in Table 6. Based on the assumptions, the number of surviving K-LTCI applicants among the projected population is simulated.

- Step 3. Distribution of surviving K-LTCI applicants in each grade: The simulated number of surviving K-LTCI applicants is distributed according to the selected mixture models derived in Section 5. For each surviving K-LTCI applicant, a score is simulated using inverse transform method and then assigned a grade under the current K-LTCI grading system.

- Step 4. Proportion of surviving applicants with dementia in Non-grades A, B, and C: there are persons 
Table 8: Projected number of beneficiaries under age 65 based on the Middle scenario

\begin{tabular}{|c|c|c|c|c|c|}
\hline \multirow[b]{2}{*}{ Year } & \multirow[b]{2}{*}{ Grade } & \multicolumn{2}{|c|}{ Male } & \multicolumn{2}{|c|}{ Female } \\
\hline & & $\begin{array}{c}\text { Number of } \\
\text { beneficiaries }\end{array}$ & $\begin{array}{r}\text { Standard } \\
\text { deviation }\end{array}$ & $\begin{array}{c}\text { Number of } \\
\text { beneficiaries }\end{array}$ & $\begin{array}{l}\text { Standard } \\
\text { deviation }\end{array}$ \\
\hline \multirow{6}{*}{2030} & Grade 1 & 2,583 & 50.76 & 2,329 & 48.06 \\
\hline & Grade 2 & 3,346 & 57.29 & 2,731 & 52.05 \\
\hline & Grade 3 & 6,112 & 78.23 & 4,254 & 64.90 \\
\hline & Grade 4 & 5,994 & 77.41 & 3,822 & 60.80 \\
\hline & Grade 5 & 755 & 27.36 & 593 & 24.29 \\
\hline & Cognitive assistance & 18 & 4.26 & 120 & 10.90 \\
\hline \multirow{6}{*}{2040} & Grade 1 & 2,235 & 47.01 & 2,008 & 45.34 \\
\hline & Grade 2 & 2,897 & 53.45 & 2,353 & 48.12 \\
\hline & Grade 3 & 5,287 & 72.90 & 3,667 & 60.44 \\
\hline & Grade 4 & 5,188 & 71.46 & 3,294 & 57.57 \\
\hline & Grade 5 & 654 & 25.34 & 510 & 22.64 \\
\hline & Cognitive assistance & 16 & 3.99 & 104 & 10.17 \\
\hline \multirow{6}{*}{2050} & Grade 1 & 1,907 & 43.63 & 1,719 & 41.50 \\
\hline & Grade 2 & 2,470 & 49.56 & 2,016 & 45.11 \\
\hline & Grade 3 & 4,511 & 67.20 & 3,139 & 56.26 \\
\hline & Grade 4 & 4,425 & 65.61 & 2,821 & 53.37 \\
\hline & Grade 5 & 557 & 23.57 & 437 & 21.01 \\
\hline & Cognitive assistance & 13 & 3.65 & 89 & 9.49 \\
\hline \multirow{6}{*}{2060} & Grade 1 & 1,573 & 40.26 & 1,455 & 37.90 \\
\hline & Grade 2 & 2,039 & 45.28 & 1,707 & 41.58 \\
\hline & Grade 3 & 3,722 & 60.58 & 2,660 & 51.32 \\
\hline & Grade 4 & 3,652 & 60.55 & 2,388 & 48.73 \\
\hline & Grade 5 & 460 & 21.69 & 370 & 19.37 \\
\hline & Cognitive assistance & 11 & 3.31 & 75 & 8.66 \\
\hline
\end{tabular}

with dementia who are eligible for K-LTCI benefit in Non-grade A, B, and C. Therefore, the simulated numbers in the score range 45.0-50.9 should be separated into Grade 5 and Non-grade A. Likewise, the simulated numbers in the score range 31.3-44.9 should be divided into the numbers in Cognitive Assistance and in Non-grades B and C. Using experience data for three years, the assumptions for the proportion of beneficiaries in Grade 5 with K-LTCI score between 45.0-50.9 and the proportion of beneficiaries in Cognitive Assistance with K-LTCI score between 31.3-44.9 were set as presented in Table 7. Based on the assumption, the number of beneficiaries in Grade 5 and in Cognitive Assistance was simulated.

- Step 5. Repeat Step 2 through Step 4 for each population projection assumption in Step 1)

Finally, the estimated number of beneficiaries in each grade in years 2030, 2040, and 2050, and its variability were obtained after 10,000 simulations. The results are summarized in Tables $8-13$. As expected, the number of K-LTCI beneficiaries under age 65 is projected to decrease over time owing to the decreased in population size. However, the number of beneficiaries over age 65 will increase up to 2050 and decrease thereafter. Since K-LTCI beneficiaries are clustered toward the older ages, long-term care expenditures will be a significant burden to both individual and the government. Therefore, a model for K-LTCI expenditure, considering all elements affecting the cost, needs to be constructed to obtain a reliable estimation on the future cost of long-term care provided by K-LTCI. This will allow us to build the necessary infrastructure such as long-term care facilities and adequate caregiving resources to meet the high future demand for long-term care. 
Table 9: Projected number of beneficiaries under age 65 based on the High scenario

\begin{tabular}{|c|c|c|c|c|c|}
\hline \multirow[b]{2}{*}{ Year } & \multirow[b]{2}{*}{ Grade } & \multicolumn{2}{|c|}{ Male } & \multicolumn{2}{|c|}{ Female } \\
\hline & & $\begin{array}{c}\text { Number of } \\
\text { beneficiaries }\end{array}$ & $\begin{array}{l}\text { Standard } \\
\text { deviation }\end{array}$ & $\begin{array}{c}\text { Number of } \\
\text { beneficiaries }\end{array}$ & $\begin{array}{l}\text { Standard } \\
\text { deviation }\end{array}$ \\
\hline \multirow{6}{*}{2030} & Grade 1 & 2,662 & 51.31 & 2,380 & 48.49 \\
\hline & Grade 2 & 3,450 & 58.23 & 2,791 & 52.67 \\
\hline & Grade 3 & 6,299 & 79.52 & 4,347 & 65.97 \\
\hline & Grade 4 & 6,179 & 78.30 & 3,904 & 63.53 \\
\hline & Grade 5 & 779 & 27.72 & 606 & 24.67 \\
\hline & Cognitive Assistance & 19 & 4.36 & 123 & 11.16 \\
\hline \multirow{6}{*}{2040} & Grade 1 & 2,366 & 48.41 & 2,117 & 45.86 \\
\hline & Grade 2 & 3,066 & 55.49 & 2,484 & 49.32 \\
\hline & Grade 3 & 5,599 & 74.47 & 3,868 & 62.14 \\
\hline & Grade 4 & 5,492 & 74.67 & 3,475 & 58.90 \\
\hline & Grade 5 & 692 & 26.18 & 539 & 23.16 \\
\hline & Cognitive Assistance & 17 & 4.03 & 109 & 10.50 \\
\hline \multirow{6}{*}{2050} & Grade 1 & 2,081 & 46.26 & 1,883 & 43.35 \\
\hline & Grade 2 & 2,697 & 52.12 & 2,208 & 47.01 \\
\hline & Grade 3 & 4,923 & 69.78 & 3,440 & 58.89 \\
\hline & Grade 4 & 4,829 & 69.39 & 3,090 & 55.79 \\
\hline & Grade 5 & 608 & 24.83 & 479 & 21.99 \\
\hline & Cognitive Assistance & 15 & 3.85 & 97 & 9.97 \\
\hline \multirow{6}{*}{2060} & Grade 1 & 1,808 & 42.37 & 1,694 & 41.15 \\
\hline & Grade 2 & 2,343 & 48.05 & 1,986 & 44.40 \\
\hline & Grade 3 & 4,278 & 64.18 & 3,094 & 56.13 \\
\hline & Grade 4 & 4,195 & 64.62 & 2,779 & 52.14 \\
\hline & Grade 5 & 529 & 23.04 & 431 & 20.80 \\
\hline & Cognitive Assistance & 13 & 3.59 & 87 & 9.36 \\
\hline
\end{tabular}

Table 10: Projected number of beneficiaries under age 65 based on the Low scenario

\begin{tabular}{|c|c|c|c|c|c|}
\hline \multirow[b]{2}{*}{ Year } & \multirow[b]{2}{*}{ Grade } & \multicolumn{2}{|c|}{ Male } & \multicolumn{2}{|c|}{ Female } \\
\hline & & $\begin{array}{c}\text { Number of } \\
\text { beneficiaries }\end{array}$ & $\begin{array}{l}\text { Standard } \\
\text { deviation }\end{array}$ & $\begin{array}{c}\text { Number of } \\
\text { beneficiaries }\end{array}$ & $\begin{array}{l}\text { Standard } \\
\text { deviation }\end{array}$ \\
\hline \multirow{6}{*}{2030} & Grade 1 & 2,518 & 50.54 & 2,247 & 47.45 \\
\hline & Grade 2 & 3,262 & 57.31 & 2,636 & 51.64 \\
\hline & Grade 3 & 5,957 & 77.23 & 4,105 & 64.53 \\
\hline & Grade 4 & 5,842 & 75.53 & 3,686 & 60.97 \\
\hline & Grade 5 & 737 & 27.01 & 571 & 23.81 \\
\hline & Cognitive Assistance & 18 & 4.23 & 116 & 10.74 \\
\hline \multirow{6}{*}{2040} & Grade 1 & 2,117 & 45.51 & 1,868 & 43.19 \\
\hline & Grade 2 & 2,743 & 52.07 & 2,189 & 46.76 \\
\hline & Grade 3 & 5,007 & 71.02 & 3,412 & 58.79 \\
\hline & Grade 4 & 4,912 & 69.80 & 3,065 & 55.66 \\
\hline & Grade 5 & 619 & 24.71 & 475 & 21.83 \\
\hline & Cognitive Assistance & 15 & 3.84 & 97 & 9.87 \\
\hline \multirow{6}{*}{2050} & Grade 1 & 1,744 & 41.77 & 1,527 & 38.76 \\
\hline & Grade 2 & 2,261 & 47.53 & 1,790 & 42.39 \\
\hline & Grade 3 & 4,128 & 64.70 & 2,790 & 52.28 \\
\hline & Grade 4 & 4,049 & 63.45 & 2,506 & 50.43 \\
\hline & Grade 5 & 510 & 22.61 & 389 & 19.76 \\
\hline & Cognitive Assistance & 12 & 3.50 & 79 & 8.85 \\
\hline \multirow{6}{*}{2060} & Grade 1 & 1,368 & 37.13 & 1,211 & 35.03 \\
\hline & Grade 2 & 1,774 & 42.24 & 1,421 & 37.52 \\
\hline & Grade 3 & 3,237 & 56.42 & 2,213 & 47.04 \\
\hline & Grade 4 & 3,175 & 56.26 & 1,988 & 44.32 \\
\hline & Grade 5 & 400 & 19.77 & 308 & 17.17 \\
\hline & Cognitive Assistance & 10 & 3.10 & 62 & 7.93 \\
\hline
\end{tabular}


Table 11: Projected number of beneficiaries over age 65 based on the Middle scenario

\begin{tabular}{|c|c|c|c|c|c|}
\hline \multirow[b]{2}{*}{ Year } & \multirow[b]{2}{*}{ Grade } & \multicolumn{2}{|c|}{ Male } & \multicolumn{2}{|c|}{ Female } \\
\hline & & $\begin{array}{c}\text { Number of } \\
\text { beneficiaries }\end{array}$ & $\begin{array}{l}\text { Standard } \\
\text { deviation }\end{array}$ & $\begin{array}{c}\text { Number of } \\
\text { beneficiaries }\end{array}$ & $\begin{array}{l}\text { Standard } \\
\text { deviation }\end{array}$ \\
\hline \multirow{6}{*}{2030} & Grade 1 & 19,078 & 137.67 & 45,843 & 213.54 \\
\hline & Grade 2 & 48,187 & 213.81 & 128,160 & 355.42 \\
\hline & Grade 3 & 126,521 & 350.90 & 314,130 & 549.44 \\
\hline & Grade 4 & 179,273 & 420.40 & 455,202 & 654.01 \\
\hline & Grade 5 & 44,434 & 211.16 & 102,406 & 316.33 \\
\hline & Cognitive Assistance & 5,670 & 75.10 & 11,914 & 109.84 \\
\hline \multirow{6}{*}{2040} & Grade 1 & 25,731 & 158.44 & 60,007 & 246.18 \\
\hline & Grade 2 & 64,988 & 255.45 & 167,754 & 405.34 \\
\hline & Grade 3 & 170,641 & 407.58 & 411,198 & 631.12 \\
\hline & Grade 4 & 241,779 & 482.08 & 595,830 & 747.40 \\
\hline & Grade 5 & 59,924 & 243.68 & 134,043 & 365.85 \\
\hline & Cognitive Assistance & 7,645 & 86.66 & 15,595 & 123.91 \\
\hline \multirow{6}{*}{2050} & Grade 1 & 28,641 & 168.68 & 65,733 & 253.41 \\
\hline & Grade 2 & 72,342 & 265.18 & 183,747 & 430.85 \\
\hline & Grade 3 & 189,958 & 433.83 & 450,389 & 652.54 \\
\hline & Grade 4 & 269,148 & 516.93 & 652,629 & 781.52 \\
\hline & Grade 5 & 66,705 & 257.08 & 146,830 & 380.83 \\
\hline & Cognitive Assistance & 8,509 & 93.11 & 17,082 & 131.28 \\
\hline \multirow{6}{*}{2060} & Grade 1 & 25,731 & 158.44 & 60,007 & 246.18 \\
\hline & Grade 2 & 64,988 & 255.45 & 167,754 & 405.34 \\
\hline & Grade 3 & 170,641 & 407.58 & 411,198 & 631.12 \\
\hline & Grade 4 & 241,779 & 482.08 & 595,830 & 747.40 \\
\hline & Grade 5 & 59,924 & 243.68 & 134,043 & 365.85 \\
\hline & Cognitive Assistance & 7,645 & 86.66 & 15,595 & 123.91 \\
\hline
\end{tabular}

Table 12: Projected number of beneficiaries over age 65 based on the High scenario

\begin{tabular}{|c|c|c|c|c|c|}
\hline \multirow[b]{2}{*}{ Year } & \multirow[b]{2}{*}{ Grade } & \multicolumn{2}{|c|}{ Male } & \multicolumn{2}{|c|}{ Female } \\
\hline & & $\begin{array}{c}\text { Number of } \\
\text { beneficiaries }\end{array}$ & $\begin{array}{l}\text { Standard } \\
\text { deviation }\end{array}$ & $\begin{array}{c}\text { Number of } \\
\text { beneficiaries }\end{array}$ & $\begin{array}{l}\text { Standard } \\
\text { deviation }\end{array}$ \\
\hline \multirow{6}{*}{2030} & Grade 1 & 19,394 & 139.37 & 47,437 & 219.20 \\
\hline & Grade 2 & 48,987 & 221.15 & 132,622 & 358.03 \\
\hline & Grade 3 & 128,621 & 353.60 & 325,071 & 557.02 \\
\hline & Grade 4 & 182,247 & 422.24 & 471,031 & 663.71 \\
\hline & Grade 5 & 45,165 & 211.80 & 105,971 & 324.40 \\
\hline & Cognitive Assistance & 5,764 & 74.94 & 12,331 & 110.70 \\
\hline \multirow{6}{*}{2040} & Grade 1 & 26,611 & 164.69 & 63,021 & 247.42 \\
\hline & Grade 2 & 67,203 & 257.22 & 176,186 & 418.61 \\
\hline & Grade 3 & 176,463 & 414.97 & 431,852 & 639.56 \\
\hline & Grade 4 & 250,027 & 494.69 & 625,748 & 777.23 \\
\hline & Grade 5 & 61,961 & 245.62 & 140,781 & 370.75 \\
\hline & Cognitive Assistance & 7,905 & 88.38 & 16,379 & 128.43 \\
\hline \multirow{6}{*}{2050} & Grade 1 & 30,138 & 173.56 & 70,304 & 262.64 \\
\hline & Grade 2 & 76,114 & 276.82 & 196,543 & 441.63 \\
\hline & Grade 3 & 199,854 & 441.03 & 481,744 & 677.16 \\
\hline & Grade 4 & 283,174 & 522.51 & 698,064 & 802.74 \\
\hline & Grade 5 & 70,177 & 265.49 & 157,053 & 390.57 \\
\hline & Cognitive Assistance & 8,953 & 94.90 & 18,273 & 134.24 \\
\hline \multirow{6}{*}{2060} & Grade 1 & 31,048 & 174.85 & 69,414 & 263.64 \\
\hline & Grade 2 & 78,405 & 277.52 & 194,060 & 434.16 \\
\hline & Grade 3 & 205,868 & 447.67 & 475,661 & 676.46 \\
\hline & Grade 4 & 291,707 & 530.67 & 689,242 & 808.10 \\
\hline & Grade 5 & 72,298 & 265.90 & 155,068 & 389.42 \\
\hline & Cognitive Assistance & 9,221 & 95.84 & 18,041 & 135.68 \\
\hline
\end{tabular}


Table 13: Projected number of beneficiaries over age 65 based on the Low scenario

\begin{tabular}{|c|c|c|c|c|c|}
\hline \multirow[b]{2}{*}{ Year } & \multirow[b]{2}{*}{ Grade } & \multicolumn{2}{|c|}{ Male } & \multicolumn{2}{|c|}{ Female } \\
\hline & & $\begin{array}{c}\text { Number of } \\
\text { beneficiaries }\end{array}$ & $\begin{array}{l}\text { Standard } \\
\text { deviation }\end{array}$ & $\begin{array}{c}\text { Number of } \\
\text { beneficiaries }\end{array}$ & $\begin{array}{l}\text { Standard } \\
\text { deviation }\end{array}$ \\
\hline \multirow{6}{*}{2030} & Grade 1 & 18,717 & 136.68 & 45,997 & 215.07 \\
\hline & Grade 2 & 47,273 & 217.47 & 128,585 & 353.57 \\
\hline & Grade 3 & 124,134 & 346.60 & 315,177 & 548.02 \\
\hline & Grade 4 & 175,882 & 416.32 & 456,707 & 652.24 \\
\hline & Grade 5 & 43,589 & 207.09 & 102,753 & 317.45 \\
\hline & Cognitive Assistance & 5,562 & 74.00 & 11,955 & 108.69 \\
\hline \multirow{6}{*}{2040} & Grade 1 & 24,761 & 155.62 & 59,247 & 241.23 \\
\hline & Grade 2 & 62,537 & 247.59 & 165,620 & 404.96 \\
\hline & Grade 3 & 164,211 & 399.31 & 405,954 & 624.04 \\
\hline & Grade 4 & 232,651 & 473.19 & 588,256 & 742.36 \\
\hline & Grade 5 & 57,662 & 238.96 & 132,342 & 362.76 \\
\hline & Cognitive Assistance & 7,356 & 86.29 & 15,399 & 124.93 \\
\hline \multirow{6}{*}{2050} & Grade 1 & 27,056 & 163.93 & 63,626 & 250.38 \\
\hline & Grade 2 & 68,334 & 260.58 & 177,867 & 414.33 \\
\hline & Grade 3 & 179,422 & 416.09 & 435,971 & 643.09 \\
\hline & Grade 4 & 254,230 & 488.29 & 631,740 & 761.41 \\
\hline & Grade 5 & 63,007 & 249.93 & 142,129 & 375.98 \\
\hline & Cognitive Assistance & 8,039 & 90.03 & 16,538 & 129.36 \\
\hline \multirow{6}{*}{2060} & Grade 1 & 27,081 & 164.91 & 60,317 & 245.65 \\
\hline & Grade 2 & 68,399 & 259.39 & 168,605 & 409.54 \\
\hline & Grade 3 & 179,602 & 419.84 & 413,290 & 626.24 \\
\hline & Grade 4 & 254,475 & 498.27 & 598,851 & 746.33 \\
\hline & Grade 5 & 63,073 & 247.09 & 134,728 & 361.43 \\
\hline & Cognitive Assistance & 8,047 & 90.07 & 15,675 & 123.30 \\
\hline
\end{tabular}

\section{Conclusion}

The demand for long-term care for an individual and its associated costs are expected to increase as citizens are living longer than before and are therefore, more likely to require assistance to do so. Furthermore, due to low fertility rates in recent years, the proportion of elderly population is set to increase resulting in higher social infrastructure and long-term care expenditure needs. K-LTCI has been playing an important role as a social security system, providing support for the elderly who need long-term care. Proper planning to finance future costs of K-LTCI is crucial to maintaining its sustainability.

Several approaches to project future demand for K-LTCI have been suggested ever since the plan was introduced. One of the approaches utilize K-LTCI score distribution to estimate the number of beneficiaries in each grade of K-LTCI as the type and amount of benefit depends on the grade determined by K-LTCI score. This study explored mixture models based on empirical K-LTCI score distribution and compared them with the spliced models suggested by previous studies. Based on simulation using the developed mixture distributions, the number of beneficiaries in each grade and its variability were estimated. However, as there has been no study on K-LTCI demand projection based on the current grading system launched in 2018, this study hopes to initiate an up-to-date discussion.

It was observed that mixture distribution can be a good model for K-LTCI score distribution. The model can be utilized to project future K-LTCI beneficiaries as illustrated in this study. Securing experience data regarding K-LTCI cost for each age group, sex, and grade provide for projection of K-LTCI costs. Also, the developed model can be utilized to evaluate the effect of any possible change in the K-LTCI grading system in case of further revision of the grading system. The appropriateness of a model should be regularly tested and developed using updated and more detailed experience data. In addition, consideration of other methods for estimating model parameters of mixture distribution such as minimizing discrepancy between model output and empirical data is a possible area of future research.

The eventual goal of the discussion is to construct a comprehensive model for funding the K-LTCI. 
Since there are many elements of the K-LTCI system, factors affecting the cash flow of the program should be studied and carefully reflected in the model. Also, the role of individual health insurance and its management, which complements K-LTCI is another possible area for further research.

\section{Appendix:}

Candidate mixture models and comparison of metrics of goodness-of-fit

(1) Males under 65

\begin{tabular}{|c|c|c|c|c|c|c|}
\hline Model No. & \multicolumn{2}{|c|}{$f_{1}(x)$} & $f_{2}(x)$ & AIC & BIC & MAPE \\
\hline 1 & \multicolumn{2}{|c|}{ Burr } & Burr & $58,498.58$ & $58,490.02$ & 0.0854 \\
\hline 2 & \multicolumn{2}{|c|}{ Inverse Burr } & Inverse Paralogistic & $58,498.72$ & $58,491.39$ & 0.9261 \\
\hline 3 & \multicolumn{2}{|c|}{ Burr } & Inv Burr & $58,499.05$ & $58,490.50$ & 0.5215 \\
\hline 4 & \multicolumn{2}{|c|}{ Inverse Paralogistic } & Inverse Paralogistic & $58,531.70$ & $58,525.59$ & 4.0634 \\
\hline 5 & \multicolumn{2}{|c|}{ Inverse Burr } & Inverse Burr & $58,571.32$ & $58,562.77$ & 6.0400 \\
\hline & \multicolumn{6}{|c|}{ CDF value at $x$} \\
\hline$x$ & Empirical & Model 1 & Model 2 & Model 3 & Model 4 & Model 5 \\
\hline 31.3 & 0.0000 & 0.0000 & 0.0000 & 0.0000 & 0.0000 & 0.0000 \\
\hline 45.0 & 0.0658 & 0.0658 & 0.0652 & 0.0662 & 0.1377 & 0.0754 \\
\hline 51.0 & 0.2069 & 0.2070 & 0.2093 & 0.2065 & 0.2776 & 0.1996 \\
\hline 60.0 & 0.5088 & 0.5089 & 0.5079 & 0.5090 & 0.5884 & 0.5160 \\
\hline 75.0 & 0.7970 & 0.7972 & 0.7975 & 0.7968 & 0.8633 & 0.7939 \\
\hline 95.0 & 0.8950 & 0.8949 & 0.8952 & 0.8960 & 0.9717 & 0.8975 \\
\hline 154.3 & 1.0000 & 1.0000 & 1.0000 & 1.0000 & 1.0000 & 1.0000 \\
\hline
\end{tabular}

(2) Females under 65

\begin{tabular}{cccccc}
\hline \hline Model No. & $f_{1}(x)$ & $f_{2}(x)$ & AIC & BIC & MAPE \\
\hline 1 & Burr & Burr & $40,234.92$ & $40,226.37$ & 0.0009 \\
2 & Inverse Burr & Inverse Burr & $40,234.92$ & $40,226.37$ & 0.0130 \\
3 & Inverse Paralogistic & Inverse Paralogistic & $40,236.74$ & $40,230.63$ & 1.6614 \\
4 & Burr & Inverse Weibull & $40,239.02$ & $40,231.69$ & 1.9729 \\
5 & Burr & Inverse Paralogistic & $40,239.03$ & $40,231.70$ & 1.9736 \\
\hline \hline
\end{tabular}

\begin{tabular}{ccccccc}
\hline \hline & \multicolumn{9}{c}{ CDF value at $x$} \\
\cline { 2 - 6 }$x$ & Empirical & Model 1 & Model 2 & Model 3 & Model 4 & Model 5 \\
\hline 31.3 & 0.0000 & 0.0000 & 0.0000 & 0.0000 & 0.0000 & 0.0000 \\
45.0 & 0.0572 & 0.0573 & 0.0573 & 0.0919 & 0.0390 & 0.0596 \\
51.0 & 0.1931 & 0.1932 & 0.1932 & 0.2235 & 0.1907 & 0.1908 \\
60.0 & 0.4699 & 0.4699 & 0.4700 & 0.4974 & 0.4746 & 0.4746 \\
75.0 & 0.7514 & 0.7515 & 0.7516 & 0.7643 & 0.7507 & 0.7507 \\
95.0 & 0.8677 & 0.8678 & 0.8678 & 0.8821 & 0.8686 & 0.8686 \\
154.3 & 1.0000 & 1.0000 & 1.0000 & 1.0000 & 1.0000 & 1.0000 \\
\hline \hline
\end{tabular}

(3) Males over 65

\begin{tabular}{cccccc}
\hline \hline Model No. & $f_{1}(x)$ & $f_{2}(x)$ & AIC & BIC & MAPE \\
\hline 1 & Inverse Paralogistic & Inv Weibull & $790,395.23$ & $790,389.12$ & 0.0022 \\
2 & Inverse Paralogistic & Inverse Gamma & $790,395.23$ & $790,389.12$ & 0.0051 \\
3 & Inverse Weibull & Inverse Weibull & $790,395.81$ & $790,389.70$ & 0.1716 \\
4 & Inverse Burr & Inverse Paralogistic & $790,397.23$ & $790,389.90$ & 0.0014 \\
5 & Burr & Inverse Gamma & $790,399.23$ & $790,390.68$ & 0.0015 \\
\hline \hline
\end{tabular}




\begin{tabular}{ccccccc}
\hline \hline & \multicolumn{5}{c}{ CDF value at $x$} \\
\cline { 2 - 6 }$x$ & Empirical & Model 1 & Model 2 & Model 3 & Model 4 & Model 5 \\
\hline 31.3 & 0.0000 & 0.0000 & 0.0000 & 0.0000 & 0.0000 & 0.0000 \\
45.0 & 0.1152 & 0.1254 & 0.1390 & 0.1160 & 0.1263 & 0.1232 \\
51.0 & 0.2795 & 0.2896 & 0.3033 & 0.2804 & 0.2906 & 0.2874 \\
60.0 & 0.6344 & 0.6446 & 0.6582 & 0.6355 & 0.6455 & 0.6424 \\
75.0 & 0.8774 & 0.8875 & 0.9012 & 0.8786 & 0.8885 & 0.8853 \\
95.0 & 0.9586 & 0.9687 & 0.9823 & 0.9596 & 0.9697 & 0.9665 \\
154.3 & 1.0000 & 1.0000 & 1.0000 & 1.0000 & 1.0000 & 1.0000 \\
\hline \hline
\end{tabular}

(4) Females over 65

\begin{tabular}{|c|c|c|c|c|c|}
\hline Model No. & $f_{1}(x)$ & $f_{2}(x)$ & AIC & $\mathrm{BIC}$ & MAPE \\
\hline 1 & Inverse Paralogistic & Inv Weibull & $2,131,460.64$ & $2,131,454.53$ & 0.0008 \\
\hline 2 & Inverse Paralogistic & Inverse Paralogistic & $2,131,460.64$ & $2,131,454.53$ & 0.0019 \\
\hline 3 & Inverse Paralogistic & Inverse Gamma & $2,131,460.64$ & $2,131,454.53$ & 0.0053 \\
\hline 4 & Inverse Burr & Inverse Paralogistic & $2,131,462.64$ & $2,131,455.31$ & 0.0076 \\
\hline 5 & Burr & Inverse Weibull & $2,131,462.64$ & $2,131,455.31$ & 0.0075 \\
\hline
\end{tabular}

\begin{tabular}{ccccccc}
\hline \hline & \multicolumn{5}{c}{ CDF value at $x$} \\
\cline { 2 - 6 }$x$ & Empirical & Model 1 & Model 2 & Model 3 & Model 4 & Model 5 \\
\hline 31.3 & 0.0000 & 0.0000 & 0.0000 & 0.0000 & 0.0000 & 0.0000 \\
45.0 & 0.0899 & 0.0907 & 0.0907 & 0.0962 & 0.0906 & 0.0929 \\
51.0 & 0.2569 & 0.2577 & 0.2577 & 0.2631 & 0.2576 & 0.2599 \\
60.0 & 0.6295 & 0.6303 & 0.6303 & 0.6358 & 0.6302 & 0.6325 \\
75.0 & 0.8662 & 0.8671 & 0.8670 & 0.8725 & 0.8670 & 0.8693 \\
95.0 & 0.9575 & 0.9583 & 0.9583 & 0.9638 & 0.9582 & 0.9605 \\
154.3 & 1.0000 & 1.0000 & 1.0000 & 1.0000 & 1.0000 & 1.0000 \\
\hline \hline
\end{tabular}

\section{References}

Chan WS, Li SH, and Fong PW (2004). An actuarial analysis of long-term care demand in Hong Kong, Geriatrics and Gerontology International, 4, 143-145.

Choi ID and Lee HY (2011). Projection of long-term care insurance beneficiary and financing, Journal of Korean Gerontological Society, 31, 1047-1065.

Choi ID, Lee SL, and Lee JM (2010). Projection of long-term care insurance: beneficiary and, personnel and facility, Journal of the Korean Social Security Association, 26, 375-400.

Karlsson M, Mayhew L, Plumb R, and Rickayzen B (2006). Future costs for long-term care: cost projection for long-term care for older people in the United Kingdom, Health Policy, 75, 187-213.

Kim H and Kwon S (2012). Projection of demand and expenditure for services under long-term care insurance for the elderly in Korea, The Korean Journal of Health Economics and Policy, 18, 29-51.

Klugman SA, Panjer HH, and Willmot GE (2019). Loss Models: From Data to Decisions, Wiley, New Jersey.

Kwon H (2013). Actuarial analysis of long term care insurance for the elderly in Korea, The Korean Journal of Applied Statistics, 26, 725-736.

Kwon HS, Ko B, and Kim JH (2016). Actuarial applications of a statistical model for long-term care insurance operated with a score-based grading system: a case study of Korean long-term care insurance (K-LTCI), Asia Pacific Journal of Risk and Insurance, 10, 217-243.

Kwon HS and Lee CS (2011). Estimating future needs of the Korean public long term care insurance, Journal of Insurance Academic Society, 88, 89-114.

Lagergren M, Kurube N, and Yasuhiko S (2018). Future costs of long-term care in Japan and Sweden, International Journal of Health Services, 48, 128-147.

Lee $\mathrm{H}$ and Moon Y (2017). Financial projection of long-term care insurance in according to population 
aging, Journal of the Korean Social Security Association, 33, 129-151.

Lee JW and Choi ID (2014). The supply and demand projection of national long-term care insurance for an political response, Journal of Critical Social Welfare, 43, 7-46.

Leung E (2004). Projecting the needs and cost of long-term care in Australia, Australian Actuarial Journal, 10, 343-385.

Linda P, Comas-Herrera A, Costa-Font J, Gori C, Di Maio A, Patxot C, Rothgang H, and Wittenberg R (2007). Modelling an entitlement to long-term care services for older people in Europe: projections for long-term care expenditure to 2050, Journal of European Social Policy, 17, 33-48.

Rickayzen BD and Walsh DEP (2002). A multi-state model of disability for the United Kingdom: implications for future need for long-term care for the elderly, British Actuarial Journal, 8, 341-393.

Vanella $\mathrm{P}, \mathrm{He} \beta \mathrm{M}$, and Wilke C (2020). A probabilistic projection of beneficiaries of long-term care insurance in Germany by severity of disability, Quality and Quantity, 54, 943-974.

Wittenberg R, Pickard L, Comas-Herrera A, Davis B, and Darton R (1998). Demand for Long-Term Care: Prospections of Long-Term Care Finance for Elderly People, Personal social services research unit (PSSRU), London school of Economics (LSE).

Xu X and Chen L (2019). Projection of long-term care costs in China, 2020-2050: based on the Bayesian quantile regression method, Sustainability, 11, 3530.

Yun $\mathrm{H}$ and Kwon HJ (2010). Projecting public expenditure for long-term care in Korea, Korean Journal of Health Policy and Administration, 20, 37-63. 
